- REVIEW ARTICLE

Volume 8 Issue 32016

DOl: 10.5959/eimj.v8i3.430

ARTICLE INFO

Submitted: 03-04-2016

Accepted: 12-07-2016

Online: $30-09-2016$

\section{The Impact of Problem Based Learning versus Conventional Education on Students in the Aspect of Clinical Reasoning and Problem Solving}

\author{
Ahmed Aldarmahi \\ College of Sciences and Health Professions (COSHP), \\ King Saud bin Abdulaziz University for Health Sciences \\ (KSAU-HS), Feddah, Saudi Arabia
}

To cite this article: Aldarmahi A. The impact of problem based learning versus conventional education on students in the aspect of clinical reasoning and problem solving. Education in Medicine Journal. 2016;8(3):1-10. http://dx.doi.org/10.5959/eimj.v8i3.430

To link to this article: http://dx.doi.org/10.5959/eimj.v8i3.430

\title{
ABSTRACT
}

Introduction: Problem based learning (PBL) since its first implementation is continuous to be one of the method's strongholds worldwide in medical education and also gaining ground in higher education. This curricular and structural innovation in medical education has certain advantages over the conventional lecture-based education in terms of student achievements, their abilities to learn problem solving skills and acquire knowledge about the basic and clinical sciences. Method: The literature research was conducted by using several keywords including: "PBL, education, medical, reasoning, teaching, undergraduate" (MeSH - Medical Subject Headings). PubMed and ERIC (Education Resources Information Center) were the database using for literature review. Result: The traditional teaching methods in medical and higher education show somehow a lack of keeping the traditional knowledge for long-lasting period and just memorisation of the necessary information. The problem based learning by using different format wisely has shifted this knowledge paradigm from teacher-centred to be a student-centred approach. Although, the pros and cons of problem based learning are still indistinct and varies, it's still more beneficial to the students for structuring their knowledge in clinical contexts, developing clinical reasoning processes, mounting self-directed learning skills and enhancing their intrinsic motivation for learning. Conclusion: The differences between the conventional methods and problem-based learning were covered briefly. After that, the approaches of how the medical students with PBL system, specifically improved their clinical reasoning and problem-solving skills were also demonstrated in details by over viewing some published studies in this prospectus.

Keywords: Problem based learning (PBL), Clinical resonating, Medical education, Teaching approaches, Undergraduate

CORRESPONDING AUTHOR Dr. Ahmed Aldarmahi, MMEdu, PhD, Assistant Professor, COSHP-Jeddah, King Saud bin Abdulaziz University for Health Sciences, National Guard Health Affairs - Saudi Arabia, P.O. Box 48543, Jeddah 21582 | Email: aldarmahiah@ngha.med.sa 


\section{Introduction}

The phenomenon of problem based learning (PBL) was first implemented in a medical school of McMaster University in Hamilton, Canada (1). After that, it has been adopted worldwide in leading medical schools (more than 60 medical schools around the world including 22 in the North America) and higher education institutes as an instructional innovation in the education (2). Analogously, much research has been conducted after its implementation to make it both teachers and students friendly (3). The core issues addressed in these studies were very much related to program evaluation issues, a comparison of student's achievements in medical boards and clinical performance in conventional versus problem based curricula, and examined organisational and administrative issues (4). In parallel to that, the student's attitude about the conception of this format in their higher studies and teachers will to adopt this system in their teaching skills were also the hotspot issues of some research in this field (5). Although, this learning systems has favoured the students to enhance their cognitive and professional skills in medical education, better prepared for life-long learning and retain their clinical knowledge and skills in basic sciences, but still there are certain questions/challenges need to be answered. For instance: e.g., what learning processes and strategies should be applied and experienced by the students in a specific PBL context? What difficulties may be experienced while implementing learning strategies in PBL both from the students and teachers side and most importantly how much it would be cost effective in terms of time and resources of the institutions (6). Similarly, the outcomes evaluation parameters between the PBL and conventional curricula are often difficult due to the selection procedures used by the medical schools and universities. The overview of PBL and traditional teaching method is depicted in Figure 1. Indeed, some studies have demonstrated that the comparison of lecture-based curricula versus PBL within the same school, sometimes students select specifically one track and/ or make deliberate decision for a certain program according to their own preferences (6). However, it does not undermine that, PBL imply a disadvantage in terms of factual knowledge and students always favour PBL to be an effective learning method over the lecture format in terms of inter-disciplinarily, team work and learning fun (7).

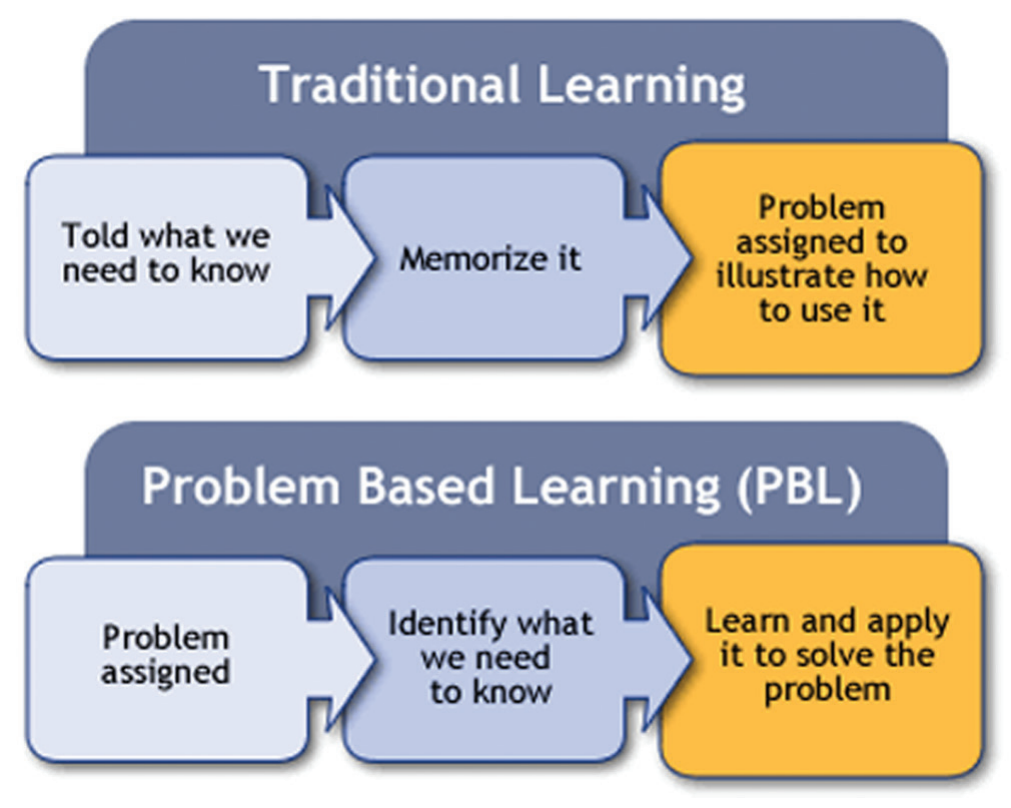

Figure 1: The overview between the traditional learning and PBL. 


\section{Problem Based Learning in Global Perspectives}

With the flurry of information in medicine and health care areas, it seems almost impossible for the teachers to teach students all the information and techniques they will need in the practice of medicine during their studies at the university (8). To keep abreast of new scientific information and new technologies, the experts in medical education and doctors should prepare the medical students to learn throughout their professional lives rather than simply to master current information and techniques (9). Active, independent, self-directed learning requires among other qualities the ability to identify, formulate, and solve problems; to grasp and use basic concepts and principles, and to gather and assess data rigorously and critically (10). In this scenario, the PBL system is continuing to be an integral part of the medical education around the world and its importance is being accepted in other education formats also, though the goals of PBL varies according to the institution's policies and vision. Its initiation in McMaster University, Hamilton, Canada in 1969, blazed the trail of student-centred, interdisciplinary teaching and learning permeating the entire medical school curriculum (1). The system with subsequent variations was adapted by a number of schools in the U.S., including New Mexico, Michigan State, Bowman Gray, Rush, Tufts, Harvard and Southern Illinois (11). Some of the expert educators from McMaster played a significant role in planning the new curricula based on PBL for the University of Hawaii and Harvard (10). Currently, many medical schools in different countries have introduced PBL in their medical education. However, the students' performance evaluation parameters vary from institutes to institutes around the world to extract and infer the successful implementation of the problem based learning. For instance, interschool comparison between students' results in PBL and conventional medical schools were mostly carried out in the U.S. and Canada, where medical school use their own criterion to select students for admission (12). Among these criteria may be suitability for the school's philosophy and its educational approach. This selection approach may be a confounding factor; it cannot be excluded that differences or similarities in students' factual knowledge, skills and attitudes are due to prior selection criteria rather than to the effects of a certain educational approach.

In Netherlands, where the allocation of places for medical studies is based upon a centralised lottery system, a comparison between a problems based learning curriculum in medical school and various conventional faculties demonstrated no significant differences between the knowledge of the students from the three medical schools involved $(13,14)$. But the drawback of the study was not using a controlled, randomised approach. A different format was applied in Harvard medical school, where the first year medical students were asked about their preference for PBL, lecture based learning (LBL) or a mixture of both (15). Then, in the first year, students were exposed to all three teaching methods in five separate courses (three problem based learning courses, one mixed, and one lecture based learning). The researchers found no differences in academic acumen within or across courses when comparing the students who preferred PBL than who favoured conventional teaching. However, the students preferences for PBL and LBL were balanced at the start of the academic year but it shifted towards a larger shift for PBL after the completion of all the courses. The Harvard policy to attract/select academically highly gifted students might be considered as a bias in such studies. A controlled, randomised study is preferable in an average medical school population to clarify the role of PBL in comparison to conventional teaching in the acquisition of factual knowledge (16).

PBL is not considered as a general educational strategy in medical schools of Germany and still there is considerable reluctance to carry out substantial reforms 
in teaching (15). Unfortunately most of the studies/discussions focus the presumed weakness of the PBL, among which one of the most prevalent concerns is that; whether PBL is able to provide future doctors/ physicians with a sound base of theoretical knowledge (17). Second, the approach is not feasible for a large number of medical students. Finally, the examination system is based to centrally administer multiplechoice questions (MCQs) which in their turn focus on detailed factual knowledge $(15,17)$.

Despite all these qualms, PBL curriculum in medical education is favourable to develop students' problem-solving skills (16). This argument is supported by two big benefits of PBL by which first it help the students to rehearse cognitive skills early in their training that are associated with clinical reasoning and second it develops thinking process, an essential characteristic of "expert" medical practice. For these reasons, PBL provides a plate form to linking early professional preparation to the contexts and processes of professional practice (16).

\section{Conventional Methods versus Problem-Based Learning System}

Conventional or traditional teaching is basically a teacher-centered approach to a large number of students (18). The curriculum is delivered through a lecturebased program. Thus, the students will passively absorb information (18). There is no integration of basic science information with the clinical skills knowledge. In addition, conventional method may not provide students with valuable skills in acquiring the information and retain it (19). On the other hand, problem-based learning (PBL) is a student-centred and requires a general prior knowledge. Thus, the students will actively acquire the knowledge rather than passively absorbing information in conventional approach (20). PBL system was introduced for first time in 1969 at McMaster University Medical School, Ontario, Canada (10).
It was based on the educational theories of Norman (21). Barrow and Tamblyn defined PBL as "Learning that results from the active process of working on a problem to understand it or resolve it" (22). Later on, Barrow redefined the PBL as "A learning method based on the principle of using problems as a starting point for the acquisition and integration of new knowledge." The PBL uses a problem as the starting point for student learning in small group of students (22). The role of teacher is facilitator. An authentic problem is presented at the beginning of the PBL tutorial with necessary prior knowledge and problem-solving skills necessary to solve the problem. New knowledge will be acquired during the tutorial and also through selfdirected learning. Several studies have showed that the PBL curriculum has a better of acquiring knowledge and retention of the information. Dolmans et al. reviewed the medical education literatures comparing students in PBL with students in standard curriculum (23). They wrote a summary for each study about the design and outcome results, and concluded that PBL improves clinical performance. Hypothesis-driven is taught in PBL system which followed frequently by PBL students.

Another earlier study performed by Boshuizen et al. demonstrated the performance and ability of knowledge integration for students from different curricula with PBL and conventional background (14). They found that students form PBL medical school used analytical approach by first exploring the biomedical aspect of the case and later linking them to clinical aspect while the approach for students from conventional background was memory-based approach.

\section{Clinical Reasoning}

Clinical reasoning is defined as "a process of making decision about various aspects of disease and health of the patients (24). Clinical teaching provides a certain degree of realism, ingenuity, and magnitude of 
patient data that are not easily available in other educational interactions. To promote clinical reasoning among the students, the teachers need to understand fundamental aspects of clinical reasoning process and target the instruction accordingly (25). It was also defined by Higgs and Jones as the thinking and/or decision-making processes that are used in clinical practice (26). In this process, the therapist interacts with the patient, structures meaning, goals and health management strategies based on clinical data, client choices, professional judgement and knowledge.

The inferences are based on a multitude of patient data and interpretation the results based on existing knowledge and experience. It will be much better when it combine with evidence-based medicine approach (27). Additionally, clinical reasoning is the process of making a series of inferences about the state of health or disease in the patients (17). Problem solving skills have touched several points of students to increase their motivation to learning and critical thinking, and improve the communication skills (17, 27).

\section{PBL Does Improve the Clinical Reasoning of the Learner}

The skills such as critical thinking, clinical reasoning, problem solving skills and decision-making were noticed and documented in students with PBL system (28). PBL system encourages the students to work and think as a team, enhance the self-directed learning and clinical reasoning. It's one of the main goals of PBL system to improve the clinical reasoning. Clinical reasoning promotes problem-solving skills and critical thinking in the learner (29). This can be achieved by teaching the clinical reasoning process to the students. It will be greatly enhanced from the understanding of the nature of reasoning process in clinical context. Barrows and Tamblyn concluded with best teaching of clinical reasoning through solving problems (22). The association between PBL and effective clinical reasoning strategies has come to much controversy. It appears that the learning of new concepts through a problem-solving process in PBL fosters the development of reasoning strategies (30). In the same conclusion, Pluta et al. (31) found that the new integrated PBL medical curriculum at the University of Liverpool is producing graduates with better communication and clinical reasoning skills than does the old traditional curriculum. Schmidt et al. (32) proved that students in PBL curriculum do better in diagnostic performance and competence compared to students in conventional school. Authors ended up with this conclusion when they compared diagnostic reasoning skills for 612 students from three different schools with PBL and conventional curricula through 30 short clinical cases. Students in PBL performed better and scored higher for diagnostic performance compared to students in conventional medical school. A local study of using PBL to enhance the clinical reasoning has been performed by Shamsan and Syed (30) in college of medicine, Qassim University, Saudi Arabia in 2009. They showed that the PBL system helps developing the students in problem solving skills. The majority of students were agreed that PBL is much better than the conventional system (30). A comparison study from two medical schools with traditional and PBL-based curriculum to diagnose a clinical case with examination of reasoning processes has been conducted (33). The PBL students advanced many more causal explanations than did those following the conventional curriculum. PBL students were able to integrate basic science and clinical knowledge compared to other conventional system students.

Small-scale studies have had mixed results. Patel et al. (33) asked 54 students from two medical schools - one with a PBL-based curriculum and the other conventional - to diagnose a clinical case and explain their diagnosis, and then examined their reasoning processes. The PBL students advanced many more causal explanations than did those following the conventional 
curriculum. They were able to integrate basic science and clinical knowledge at all levels, while the students from conventional curriculum in the preclinical years did not adequately deal with the clinical aspects of the problem. The PBL students explained the causes more extensively, using the relevant biomedical knowledge, but made more diagnostic errors.

In contrast, Boshuizen et al. (14) found that PBL significantly superior with respect to students' program, but no significant effect on clinical reasoning and the theoretical basis for PBL, contextual learning theory, is weak. In addition, Albanese and Mitchell (10) studied final-year medical students from McMaster and concluded that there was no evidence that PBL teaches problem solving better than traditional school.

In a study by Hmelo-Silver (34) in 2004, diagnostic performances were compared between medical students following PBL curriculum and those following a conventional one. At three points during the course of a year, these students were requested to produce a diagnosis and explain the underling pathophysiology of two cases. The accuracy of diagnostic hypothesis produced by PBL students increased over time, whereas the students from the conventional track did not show this increase. In addition, the PBL students showed more coherence in their pathophysiological explanations (34).

Lack of traditional structure and progression of PBL, lacking of in-depth knowledge and too much consumption of time are some of the perceived weaknesses to PBL (35). Similarly, one barrier which seems difficult to overcome in PBL is the integration of preclinical teaching materials with those of clinical teaching where teachers in these two areas often work in isolation. Confusion may arise for the teachers who equate PBL with problem solving ability (31). PBL is a process of learning using a problem as a starting point, whereas problem solving ability is the application of the knowledge acquired to solve the problem. However, these words are still used interchangeably or it is assumed that PBL is a means to the end of acquiring problem-solving skills. It is not true in its original sense because studies have shown that the expert is distinguished not by any general skills, but by the possession of appropriate knowledge to resolve the problem $(31,35)$.

\section{Elements of Concerns for Students Entering PBL}

The students entering the medical education program in some universities have an undergraduate degree but mostly in universities high school graduates are admitted directly into medical program (22). Some education expert thinks that the high school graduate students lack the level of maturity for them to succeed in a PBL program (15). However, some studies indicate that by some necessary training, the morale of high school graduates may be elevated to an extent to benefit from the PBL approach (16). For this purpose, a serial of lectures and small workshops may be conducted during their first year preparatory year program to sharpen the students cognitive skills and to acquaint them about the dos and don'ts of the PBL (31).

Second big concern which must be in mind relates to the students science background. A study conducted in North America to evaluate the performance of first year students without the usual prerequisites to attend medical school across four classes demonstrated no differences in performances. The perceptions of the students for medical curriculum were almost similar and there was also no difference in their choice of specialty, location and type of practice. The researchers also could not find differences of the performance between those with or without a science background (8). Although it is still controversial about the same aptitude of PBL between science background and non-scientific students, but it appears from the studies that students with non-science background are able 
to adapt quickly and catch up with their classmates (31).

Cultural background is very much concerned in Asia where the teachers wonder and conscious about their students' approach in PBL format (36). The predisposing factor is the passive behaviour of the students toward their teachers, in contrast with the students in The U.S. and Europe, where the students are generally more out-spoken. Interestingly, still there is no evident research/report to support this concern.

\section{Tutor's Role in Problem Based Learning}

A lot of studies clearly demonstrate that a qualified tutor can play an essential role in PBL and clinical reasoning as it is uniformly agreed by the students participating in the proposed studies (36). Indeed, without a skilled, professional and knowledgeable teacher, PBL would be chaotic or disastrous. It may happen because many university teachers come directly from baccalaureates and graduate programs with little or no pedagogic content and their performance evaluation in university is based on research accomplishments than teaching performance (10). Thus, PBL may be a valuable tool to evaluate the teacher's values, conception and practices because PBL encounters unexpected classroom situations, post teaching dilemmas and stimulates decisionmaking which are essential elements to help students learn the content as well as develop professionally and socially desirable skills and attitudes (30). In parallel to that, although the tutor role is critical in PBL, but the students' opinions in conceptualisation and expectations of the tutor's role is always different (36). The significant studies in this prospectus define three concrete roles of the tutors including; a facilitative expertise of knowledge transfer with ability to facilitate group work, the basic science or medical craft knowledge and clinical reasoning expertise or clinical reasoning skills plus tutor knowledge of medical problem solution. The first two characteristics must be most often and the third one should be a distinct category role. Interestingly, such characteristics are expected from the tutors on their active role in PBL to which they participate in group dynamics, the development of dependency relationship with the students, students' performance expectations, tutors guidelines to the group and their working rather than serving as non-directive guides $(31,36)$. In these scenarios, the tutor's role seems complex and often contradictory especially in the situations when we consider the multiple role contents and the power dimension (31). For group sessions, as considered a core element of PBL and clinical reasoning, the students prefer moderately to highly directive, judgemental and controlled tutors to contribute the depth and breadth of their individual learning (36).

\section{Conclusion}

Knowledge is much better recalled and applied in the context in which it was originally learned. From the above mentioned studies, we may infer that PBL have a positive impact on the clinical performance of the students. PBL provides a teaching method which enhances the student skills in different levels and nicely integrate the basic and clinical knowledge. It helps to develop valuable skills such as acquiring knowledge, clinical reasoning, problem-solving and communication in team-work. It also enhances the students' retention and thinking ability rather than just memorising it. PBL students utilise a hypothesis-driven reasoning strategy for learning which fosters independent and self-directed learning. It aims to generate more coherent explanations than students without PBL experience. However, the perceived weaknesses of PBL clearly demonstrate that the assessment of using PBL curriculum to enhance the clinical reasoning and problem-solving skills need more validation approaches. Students' expectations to adopt PBL are most clearly articulated when instructional strategies are 
directly linked to the goals of PBL. Further studies, particularly from Saudi universities are needed for better judgements of using PBL system in medical schools. Similarly, research is needed to define and refine more subtle distinctions about tutor expertise and role process dimension in particular to develop the students' reasoning process.

\section{Acknowledgements}

The author thanks Dr. Mohammed Alrabia and Dr. Mohammed Khan for their kind critical review of the manuscript. The study was approved by King Abdullah International Medical Research Centre (KAIMRC) with Ref. No. RJ13/46/J.

\section{References}

1. Neufeld VR, Woodward CA, MacLeod SM. The McMaster MD program: a case study of renewal in medical education. Academic Medicine. 1989;64(8):423-32. http://dx.doi. org/10.1097/00001888-198908000-00001.

2. Barrows HS. Problem-based learning in medicine and beyond: a brief overview. New Directions for Teaching and Learning. 1996;68:3-12. http://dx.doi.org/10.1002/tl. 37219966804

3. Duch BJ, Groh SE, Allen DE. The power of problem-based learning: a practical "how to" for teaching undergraduate courses in any discipline. Sterling, VA: Stylus Publishing, LLC.; 2001

4. Palmer B, Major C. Engendering the scholarship of problem-based learning. International Journal for the Scholarship of Teaching and Learning. 2007;1(2):5. http:// dx.doi.org/10.20429/ijsotl.2007.010205.

5. Quinlan KM. Effects of problem-based learning curricula on faculty learning: new lenses, new questions. Advances in Health Sciences Education. 2003;8(3):249-59. http://dx.doi.org/10.1023/A:1026034029468.
6. de Camargo Ribeiro LR. Electrical engineering students evaluate problembased learning (PBL). International Journal of Electrical Engineering Education. 2008;45(2):152-61. http://dx.doi.org/10. 7227/IJEEE.45.2.7.

7. Wood DF. Problem based learning. British Medical Journal. 2003;326:328. http://dx. doi.org/10.1136/bmj.326.7384.328.

8. Newble D, Clarke R. The approaches to learning of students in a traditional and in an innovative problem-based medical school. Medical Education. 1986;20(4):267-73. http://dx.doi.org/10.1111/j.1365-2923.1986. tb01365.x.

9. Solomon P. Problem-based learning: a direction for physical therapy education? Physiotherapy Theory and Practice. 1994; 10(1):45-52. http://dx.doi.org/10.3109/095 93989409036386.

10. Albanese MA, Mitchell S. Problembased learning: a review of literature on its outcomes and implementation issues. Academic Medicine. 1993;68(1):52-81. http:/dx.doi.org/10.1097/00001888-1993 01000-00012.

11. Morrison J. Where now for problem based learning? The Lancet. 2004;363:174. http:// dx.doi.org/10.1016/S0140-6736(03) 1529 8-1.

12. Ribeiro LRC, Mizukami MDGN. Problembased learning: a student evaluation of an implementation in postgraduate engineering education. European Journal of Engineering Education. 2005;30(1):137-49. http://dx. doi.org/10.1080/03043790512331313796.

13. De Graaff E, Kolmos A. History of problembased and project-based learning. In: De Graaff E, Kolmos A, editors. Management of change: implementation of problem-based and project-based learning in engineering. Rotterdam/Taipei: Sense Publisher; 2007. p. $1-8$. 
14. Boshuizen H, Schmidt H, Wassamer I, editors. Curriculum style and the integration of biomedical and clinical knowledge. Second International Symposium on Problem-based Learning; 1990 October 7-12; Yogyakarta, Indonesia.

15. Wilson J. Problem-based learning revolution: reformation or an empty promise? A review of the constructivist approach to problembased learning in undergraduate medical education. Middlesex University Occasional Papers in Education and Lifelong Learning. 2007;1:44-57.

16. Amador JA, Miles L, Peters CB. The practice of problem-based learning: a guide to implementing PBL in the college classroom. Bolton: Anker Publishing Company; 2006.

17. Pradhan B, Ranjit E, Ghimire M, Dixit Y. History of problem based learning in Nepal and experiences at Kathmandu Medical College. Journal of Kathmandu Medical College. 2012;1(1):37-44. http://dx.doi.org/ 10.3126/jkmc.v1i1.7255.

18. Dewey J. Democracy and education: an introduction to the philosophy of education. New York: Macmillan Company; 2008.

19. Udovic D, Morris D, Dickman A, Postlethwait J, Wetherwax P. Workshop biology: demonstrating the effectiveness of active learning in an introductory biology course. Bioscience. 2002;52(3):272-81. http://dx.doi.org/10.1641/0006-3568(2002) 052[0272:WBDTEO]2.0.CO;2.

20. Dochy F, Segers M, Van den Bossche P, Gijbels D. Effects of problem-based learning: a meta-analysis. Learning and Instruction. 2003;13(5):533-68. http://dx.doi.org/10. 1016/S0959-4752(02)00025-7.

21. Norman G. Problem-based learning makes a difference. But why? Canadian Medical Association Journal. 2008;178(1):61-2. http://dx.doi.org/10.1503/cmaj.071590.
22. Barrows HS, Tamblyn RM. Problem-based learning: an approach to medical education. New York: Springer Publishing Company; 1980.

23. Dolmans DH, De Grave W, Wolfhagen IH, Van Der Vleuten CP. Problem-based learning: future challenges for educational practice and research. Medical Education. 2005;39(7):732-41. http://dx.doi.org/10. 1111/j.1365-2929.2005.02205.x.

24. McDonald JK, Yanchar SC, Osguthorpe RT. Learning from programmed instruction: examining implications for modern instructional technology. Educational Technology Research and Development. 2005;53(2):84-98. http://dx.doi.org/10. 1007/BF02504867.

25. Molenda $M$. When effectiveness mattered. TechTrends. 2008;52(2):53.

26. Higgs J, Jones MA. Clinical decision making and multiple problem spaces. Clinical Reasoning in the Health Professions. 2008; 3:1-18.

27. Azer SA. Problem-based learning. A critical review of its educational objectives and the rationale for its use. Saudi Medical Journal. 2001;22(4):299-305.

28. Elstein AS, Schwartz A. Clinical reasoning in medicine. In: Elstein AS, Schwartz A, editors. Clinical reasoning in the health professions Woburn, Mass: ButterworthHeinemann; 1995. p. 49-59.

29. Amin Z, Eng KH. Delivery of clinical teaching. In: Amin $\mathrm{Z}$, Eng $\mathrm{KH}$, editors. Basics in medical education. Singapore: World Scientific; 2003. p. 171-80.

30. Shamsan B, Syed AT. Evaluation of problem based learning course at college of medicine, Qassim University, Saudi Arabia. Int J Health Sci (Qassim). 2009;3(2):249-58. 
31. Pluta WJ, Richards BF, Mutnick A. PBL and beyond: trends in collaborative learning. Teaching and Learning in Medicine. 2013; 25(sup1):S9-S16.

32. Schmidt HG, Machiels-Bongaerts $M$, Hermans $\mathrm{H}$, ten Cate TJ, Venekamp R, Boshuizen $\mathrm{H}$. The development of diagnostic competence: comparison of a problembased, an integrated, and a conventional medical curriculum. Academic Medicine. 1996;71(6):658-64. http://dx.doi.org/10. 1097/00001888-199606000-00021.

33. Patel VL, Groen GJ, Norman GR. Effects of conventional and problem-based medical curricula on problem solving. Academic Medicine. 1991;66(7):380-9. http://dx.doi. org/10.1097/00001888-199107000-00002.
34. Hmelo-Silver CE. Problem-based learning: what and how do students learn? Educational Psychology Review. 2004;16(3): 235-66. http://dx.doi.org/10.1023/B:EDPR. 0000034022.16470.f3.

35. Du X, de Graaff E, Kolmos A. Research on PBL practice in engineering education. Rotterdan, The Netherlands: Sense Publishers; 2009.

36. Leung KK, Lue BH, Lee MB. Development of a teaching style inventory for tutor evaluation in problem-based learning. Medical Education. 2003;37(5):410-6. http://dx.doi.org/10.1046/j.1365-2923.2003. 01493.x. 